\title{
The First Outbreak of Crimean-Congo Hemorrhagic Fever Disease in Northwest of Iran
}

\author{
Shahram Habibzadeh ${ }^{1} \cdot$ Jafar Mohammadshahi $^{1} \cdot$ Arman Bakhshzadeh $^{2} \cdot$ Eslam Moradi-Asl $^{3}$ (i)
}

Received: 11 August 2020 / Accepted: 27 January 2021 / Published online: 6 March 2021

(c) Witold Stefański Institute of Parasitology, Polish Academy of Sciences 2021

\begin{abstract}
Purpose Crimean-Congo Hemorrhagic fever (CCHF) is a viral hemorrhagic fever which is transmitted by tick bites, or through contact with infected animal tissues or secretions during and immediately post slaughter. It can be responsible for severe outbreaks in humans.

Methods We have explained 10 patients of CCHF, which was acquired during the first outbreak in northwest of Iran. All 10 patients were admitted to our hospital and all were treated promptly by ribavirin.

Results In this outbreak, 51 blood samples were collected from suspected patients and sent to Pasteur Institute of Iran for additional assessments. CCHF was confirmed by reverse transcriptase polymerase chain reaction (RT-PCR) in $19.60 \%$ of patients.

Conclusion High movement of livestock and vectors in spring and summer seasons is one of the major causes of virus circulation in northwestern Iran.
\end{abstract}

Keywords Crimean-Congo hemorrhagic fever · Outbreak · Ardabil · Iran

\section{Introduction}

Crimean-Congo hemorrhagic fever (CCHF) is an important zoonotic viral disease often transmitted through tick bites or contact with blood and infected animal tissues. However, there is a likelihood of nosocomial infection from patients to healthy individuals [1]. The causative agent is an orthobunyavirus which belongs to the Nairoviridae family [2]. The infection remains subclinical in most cases $(\approx 90 \%$ of CCHFV infections are subclinical) [3] but the risk of death is $10-40 \%$ if symptoms appear [4]. Occupationally,

Serum samples from forty-one patients who tested negative for PCR were not tested for specific antibodies against Crimean fever during the recovery period to determine their exact diagnosis.

Eslam Moradi-Asl

moradias183@yahoo.com

1 Department of Infectious Disease and Tropical Medicine, Ardabil University of Medical Science, Ardabil, Iran

2 Medical Student School of Medicine, Ardabil University of Medical Science, Ardabil, Iran

3 Department of Public Health, School of Public Health, Ardabil University of Medical Science, Ardabil, Iran the disease mostly occurs in ranchers, farmers, butchers and slaughterhouse workers. In Fars province in southern Iran, the highest confirmed positive cases have been observed among butchery workers [5]. The disease has a worldwide distribution and most of the cases are reported in the Middle East during the summer [6]. The incubation period lasts from 1 to 13 days, largely depending on how the virus enters the human body. The onset of symptoms is sudden and begins with fever and myalgia. Other important complaints include: headache, neck pain and stiffness, backache, photophobia. Symptoms of gastrointestinal involvement may also be present, such as vomiting, diarrhea and abdominal pain, with hepatomegaly [7]. If the disease progresses, more dangerous symptoms, including jaundice, changes in mood and sensory perception, large areas of severe bruising, severe nosebleeds, and uncontrolled bleeding at injection may occur. Serious symptoms usually start on the fourth day and may last up to 2 weeks [8]. 


\section{Cases Presentation}

Between June and August 2019, ten patients were admitted to Imam Khomeini Hospital in Ardabil with an initial diagnosis of CCHF. The first patient was a man who died of severe gastrointestinal bleeding less than $24 \mathrm{~h}$ after being admitted without specific treatment (Mortality rate: $10 \%)$.

In this outbreak, 51 blood samples were collected from suspected patients and sent to Pasteur Institute of Iran for additional assessments. CCHF was confirmed by reverse transcriptase polymerase chain reaction (RT-PCR) in $19.60 \%$ of patients, in one of them, serum IgM-specific antibody test against CCHF was also positive. Serum samples were not taken during the recovery period due to lack of cooperation of improved patients.

Specific antibodies against CCHF fever were not measured during the acute period and recovery from the disease, the mean age of the patients was $34.5 \pm 11.9$ and $80 \%$ of them were male. All patients were cattle breeders or had close contact with sheep or cattle at home. $70 \%$ of patients reported a history of tick bites in the last three days, but $30 \%$ of patients did not report tick bites, although all of them knew the tick and them had repeated contact. The type of contact with ticks involved removing them from the animal's body or crushing them in various ways. The onset of symptoms was sudden in $60 \%$ of patients and the incubation period in all these patients was between one and two days. Only $20 \%$ of patients mentioned fever as the main complaint at the time of examination. Other complaints were weakness, severe muscle aches in $90 \%$, severe headache in $40 \%$, nausea with or without vomiting in $20 \%$ of patients, and tendency to bleed (only in one patient who died). The mean and standard deviation of the laboratory findings of the patients are presented in Table 1.

The most important epidemiologically significant finding was the geographic difference of patients' residence. Patients from different parts of the province were referred to the infectious ward of Imam Khomeini Hospital in Ardabil. The patients' geographical distribution is shown in Fig. 1. The results of this survey showed that most of the patients were tribes who seasonally migrate from the north to the center of province during the spring and summer seasons.

\section{Discussion}

One case of CCHF disease was reported in Ardabil previously and so far, no deaths have been reported [9]. The disease is often reported in the south and southeast of Iran and this report is the first outbreak of the disease in northwest of Iran. Ticks, particularly Hyalomma species, are the main vector and reservoir of CCHFV and different animals including livestock are amplifying hosts for the virus. The northwest of Iran has a mountainous climate and most of the people are into agriculture and animal husbandry. The tick infestation rate among livestock in this area was 9-17\% and the species composition of hard ticks on livestock comprised: Hyalomma marginatum, $H$. anatolicum, H. dromedarii, H.detritum and Rhipicephalus bursa [10]. Mostly livestock relocation occurs during spring and is one of the causes of the distribution of ticks in the area. It is recommended to control tick's use suitable as acaricide and repellents [11].

Tick bite is one of the main ways of transmitting CCHF [12]. In this report, $70 \%$ of patients had history of tick bite in the last three days. The high abundance of ticks and the high infestation of livestock can be important causes for this result. Most of the patients were male, indicating a relationship between the disease and occupation in the area. In studies conducted in Sistan and Baluchestan and Khuzestan, more than $80 \%$ of patients were male $[13,14]$. All 10 patients were admitted to our hospital and were treated promptly by ribavirin. Unfortunately, one patient was referred late to the hospital and the treatment started four days after the beginning of the first sign, who subsequently died. In this outbreak, the interval time between onset of symptoms and hospital admission was 2-3 days and therefore, all 9 cases received ribavirin therapy at the earliest possible time.

\section{Conclusion}

The present study underestimated the actual number of $\mathrm{CCHF}$ for two reasons. First, serum samples from forty-one patients who tested negative for PCR were not tested for specific antibodies against CCHF during the recovery period to determine their exact diagnosis. Second, up to $90 \%$ of patients with CCHF may remain asymptomatic, so finding ten definite positive patients among symptomatic patients indicates the presence of about 100 real patients at the time of the outbreak in Ardabil province. To evaluate the hypothesis, a serological study can be performed and IgG-specific antibodies against CCHF virus can be measured in the serum sample in appropriate sample size that can represent the reference community.

In this outbreak, the CCHF disease was reported from 10 different regions of Ardabil province and it happened during spring and summer. In these seasons, the movement of livestock and herds is very high between regions and vectors move along with livestock and virus can be transmitted between animals and humans. In the present study, the gene 
sequence of the virus has not been determined and therefore it cannot be claimed that only one virus has been spread in the province, but the absence of disease in previous years is in favor of spreading a virus with the same genome.

Acknowledgements The authors would like to thank all the staff of the ward of infectious diseases of Imam Khomeini hospital.

\section{Compliance with Ethical Standards}

Ethical Statements None.

\section{References}

1. Chinikar S, Ghiasi SM, Hewson R, Moradi M, Haeri A (2010) Crimean-Congo hemorrhagic fever in Iran and neighboring countries. J Clin Virol 47:110-114. https://doi.org/10.1016/j. jcv.2009.10.014

2. Spengler JR, Bergeron É, Spiropoulou CF (2019) CrimeanCongo hemorrhagic fever and expansion from endemic regions. Curr Opin Microbiol 34:70-78. https://doi.org/10.1016/j.covir o.2018.12.002

3. Bodur H, Akinci E, Ascioglu S, Öngürü P, Uyar Y (2012) Subclinical infections with Crimean-Congo hemorrhagic fever virus, Turkey. Emerg Infect Dis 18:640-642. https://doi.org/10.3201/ eid1804.111374

4. World Health Organization (2012) Crimean Congo hemorrhagic fever. WHO, at http://www.who.int/mediacentre/factsheets/fs208 /en/ (Accessed in 12 May, 2012)

5. Fakoorziba MR, Neghab M, Alipour H, Moemenbellah-Fard MD (2006) Tick-borne Crimean-Congo haemorrhagic fever in Fars province, southern Iran: epidemiologic characteristics and vector surveillance. Pak J Biol Sci 9:2681-2684. https://doi.org/10.3923/ pjbs

6. Emadi Koochak H, Yalda AR, Haj Abdolbagh M, Sood Bakhsh A (2003) Crimean-congo hemorrhagic fever. Tehran Univ Med J 61:343-358
7. Mostafavi E, Pourhossein B, Chinikar S (2014) Clinical symptoms and laboratory findings supporting early diagnosis of CrimeanCongo hemorrhagic fever in Iran. J med viro 86:1188-1192. https ://doi.org/10.1002/jmv.23922

8. Al-Abri SS, Al Abaidani I, Fazlalipour M, Mostafavi E, Leblebicioglu H, Pshenichnaya N, Memish ZA, Hewson R, Petersen E, Mala P, Nguyen TM (2017) Current status of CrimeanCongo haemorrhagic fever in the World Health Organization Eastern Mediterranean Region: issues, challenges, and future directions. Int J Infect Dis 58:82-89. https://doi.org/10.1016/j. ijid.2017.02.018

9. Moradi-Asl E, HabibzadehSH A-S (2019) A Case Report of Crimean-Congo Hemorrhagic Fever in Ardabil. J Ardabil Univ Med Sci 19:249-253

10. Vatandoost H, Moradi Asl E, Telmadarreiy Z, Mohebali M, Masoumi Asl H, Abai MR, Zarei Z (2012) Field efficacy of flumethrin pour-on against livestock ticks in Iran. Int J Acarol 38:457-464. https://doi.org/10.1080/01647954.2012.662245

11. Asl EM, Vatandoost H, Telmadarreiy Z, Mohebali M, Abai MR (2018) Repellency effect of flumethrin pour-on formulation against vectors of Crimean-Congo haemorrhagic fever. East Mediterr Health J 24:1082-1087. https://doi.org/10.26719/emhj.18.004

12. Sharifi-Mood B, Metanat M, Hashemi-Shahri SM, Mardani M, Hashemi SA, Fayyaz-Jahani F (2011) Crimean-Congo hemorrhagic fever following consumption of uncooked liver: case series study. Iran J Clin Infect Dis 6:128-130

13. Salehi VM, Salmanzadeh S, Baniasadi V, Jalali T, Mohammadi T, Azad MS, Jamshidi Y, Khakifirouz S, Fazlalipour M (2017) An outbreak of crimean-congo hemorrhagic fever in the south west of Iran. Jundishapur J Microbiol 10:e41735. https://doi.org/10.5812/ jjm. 41735

14. Rakhshani M, Abedi-poor F, Noori-Jangi M, Khoorgami P, Hajalizadeh A, Kooshki M, Jahantigh A, Safdari A, Abbasi A (2014) A five-member family with Crimean-Congo hemorrhagic fever; a case series study. Int J Infect 1:18421. https://doi.org/10.17795 /iji-18421

Publisher's Note Springer Nature remains neutral with regard to jurisdictional claims in published maps and institutional affiliations. 